\title{
SARS-CoV-2 detection in the lower respiratory tract of invasively ventilated ARDS patients
}

\author{
Niccolò Buetti ${ }^{1,2,3^{*+}}$ (D), Paul-Henri Wicky ${ }^{4 \dagger}$, Quentin Le Hingrat ${ }^{1,5}$, Stéphane Ruckly ${ }^{1}$, Timothy Mazzuchelli ${ }^{2}$, \\ Ambre Loiodice ${ }^{1}$, Pierpaolo Trimboli ${ }^{6,7}$, Valentina Forni Ogna ${ }^{2}$, Etienne de Montmollin ${ }^{1,4}$, Enos Bernasconi ${ }^{8}$, \\ Benoit Visseaux ${ }^{1,5}$ and Jean-François Timsit ${ }^{1,4}$
}

\begin{abstract}
Background: Data on SARS-CoV-2 load in lower respiratory tract (LRT) are scarce. Our objectives were to describe the viral shedding and the viral load in LRT and to determine their association with mortality in critically ill COVID-19 patients.

Methods: We conducted a binational study merging prospectively collected data from two COVID-19 reference centers in France and Switzerland. First, we described the viral shedding duration (i.e., time to negativity) in LRT samples. Second, we analyzed viral load in LRT samples. Third, we assessed the association between viral presence in LRT and mortality using mixed-effect logistic models for clustered data adjusting for the time between symptoms' onset and date of sampling.

Results: From March to May 2020, 267 LRT samples were performed in 90 patients from both centers. The median time to negativity was 29 (IQR 23; 34) days. Prolonged viral shedding was not associated with age, gender, cardiac comorbidities, diabetes, immunosuppression, corticosteroids use, or antiviral therapy. The LRT viral load tended to be higher in non-survivors. This difference was statistically significant after adjusting for the time interval between onset of symptoms and date of sampling (OR 3.78, 95\% Cl 1.13-12.64, $p=0.03)$.
\end{abstract}

Conclusions: The viral shedding in LRT lasted almost 30 days in median in critically ill patients, and the viral load in the LRT was associated with the 6-week mortality.

Keywords: SARS-CoV-2, COVID-19, Viral shedding, Viral load, Lower respiratory tract, ICU, Mortality

\section{Background}

The SARS-CoV-2 disseminated in Europe in late February 2020, causing the largest pandemic due to any respiratory viruses any respiratory viruses in recent history [1]. Several authors suggested that viral shedding and severity of disease might be correlated [2], but they mostly focused on viral presence in upper respiratory secretions

\footnotetext{
*Correspondence: niccolo.buetti@gmail.com

${ }^{+}$Niccolò Buetti and Paul-Henri Wicky contributed equally to this work. 'University of Paris, INSERM, IAME, F-75006 Paris, France

${ }^{2}$ Ente Ospedaliero Cantonale, Locarno Community Hospital, Locarno, Switzerland

Full list of author information is available at the end of the article
}

[3, 4]. Viral shedding from upper respiratory tract appeared to be higher soon after symptoms' onset, but during the course of disease, the shedding originates predominantly from the lower respiratory tract (LRT) [5]. To date, data on viral replication in distal airways are scarce. Only one small study partly investigated the role of viral presence into LRT [6]. Moreover, the association between SARS-CoV-2 viral load in LRT and mortality remains unevaluated [7]. Our objectives were (1) to describe the viral shedding and the viral load in LRT and (2) to determine THE ASSOCIATION BETWEEN

(c) The Author(s). 2020 Open Access This article is licensed under a Creative Commons Attribution 4.0 International License, which permits use, sharing, adaptation, distribution and reproduction in any medium or format, as long as you give appropriate credit to the original author(s) and the source, provide a link to the Creative Commons licence, and indicate if changes were made. The images or other third party material in this article are included in the article's Creative Commons licence, unless indicated otherwise in a credit line to the material. If material is not included in the article's Creative Commons licence and your intended use is not permitted by statutory regulation or exceeds the permitted use, you will need to obtain permission directly from the copyright holder. To view a copy of this licence, visit http://creativecommons.org/licenses/by/4.0/ The Creative Commons Public Domain Dedication waiver (http://creativecommons.org/publicdomain/zero/1.0/) applies to the data made available in this article, unless otherwise stated in a credit line to the data. 
VIRAL PRESENCE AND MORTALITY in critically ill COVID-19 patients.

\section{Material and methods Study design and population}

We conducted a binational study merging prospectively collected data from two COVID-19 reference centers in France and Switzerland. We included all COVID-19 patients under mechanical ventilation who underwent regularly to LRT sampling for SARS-CoV-2. The Bichat University Hospital served as a reference center for the Northern Paris Region, whereas the Locarno Regional Hospital was an entirely COVID-19-dedicated hospital for all $(n=7)$ public hospitals of southern Switzerland (Canton of Ticino).

\section{Data collection}

All data of COVID-19 patients were prospectively collected in two specific standardized institutional databases. We collected demographic characteristics, medical history, characteristics at hospital and intensive care unit (ICU) admissions, organ support procedures, administration of antivirals and other agents, and biological and virological results. Of note, prescription of antivirals and anti-inflammatory drugs varied among countries, availability, and choice of physician.

\section{Study procedures}

All patients had a SARS-CoV-2 positive nasopharyngeal swab before ICU admission. During the ICU stay, all patients underwent a regularly monitoring of LRT samples (LRTS) until the detection of two consecutive negative real-time polymerase chain reaction (RT-PCR) results [8]. All patients underwent regularly to LRT RT-PCR reevaluation until removal of the endotracheal tube or death. Endotracheal aspirates, bronchoalveolar leakage fluid, and plugged telescoping catheter were all considered as LRTS. The sampling was performed according to a predefined protocol. All specimens were sent to two accredited reference virology laboratories and used for RNA extraction and amplification by RT-PCR techniques utilizing validated commercial kits that were previously described [9]. A cycle threshold $(\mathrm{Ct})$ value of $<$ 40 was defined as positive for SARS-CoV-2 RNA and $\geq$ 40 was defined as negative (see supplementary material). Then, RT-PCR values were transformed in viral load as previously published [10]. The French and the regional Swiss Ethics Committees approved this study.

\section{Definitions and objectives}

The primary objective was the description of viral shedding duration (i.e., time to negativity) in LRTS and was defined as the time between onset of symptoms and viral clearance process (i.e., first negative detection of viral
RNA in LRT). Of note, we previously showed that the association of the first negative RT-PCR with a second negative result was very high (i.e., 97\%) in LRTS [11]. Secondary objectives were (1) the analysis of RT-PCR viral load in LRTS and (2) the assessment of 6-week mortality. Patients discharged before 6-weeks were considered alive.

\section{Statistical analysis}

The statistical plan had three steps. First, we explored the duration of viral shedding in LRT using KaplanMeier curves for different clinical relevant patient populations (i.e., age, diabetes, cardiac comorbidities, immunosuppression, and corticosteroids during the ICU stay) which are thought to influence viral shedding in upper respiratory tract samples [2, 12-15]. A log rank

Table 1 Patients' characteristics

\begin{tabular}{|c|c|}
\hline & Patients $(N=90)$ \\
\hline French center (versus Swiss center), $n(\%)$ & $42(46.7)$ \\
\hline Age, median $[\mathrm{QQR}]$ & $62.5[54 ; 70]$ \\
\hline \multicolumn{2}{|l|}{ Sex, $n(\%)$} \\
\hline Male & $71(78.9)$ \\
\hline $\mathrm{BMI}$, median $[\mathrm{IQR}]$ & $29.6[26 ; 33.3]$ \\
\hline SAPS II at ICU admission, median [IQR] & $45.5[37 ; 61]$ \\
\hline SOFA at ICU admission, median [IQR] & $7[6 ; 10]$ \\
\hline \multicolumn{2}{|l|}{ Comorbidities } \\
\hline Cardiovascular, $n(\%)$ & $36(40)$ \\
\hline Chronic respiratory failure, $n(\%)$ & $18(20)$ \\
\hline Renal failure, $n(\%)$ & $14(15.6)$ \\
\hline Immunosuppression, n (\%) & $28(31.1)$ \\
\hline Diabetes mellitus, n (\%) & $27(30)$ \\
\hline Cancer, $n(\%)$ & $4(4.4)$ \\
\hline \multicolumn{2}{|l|}{ Treatment administered } \\
\hline Ritonavir/lopinavir, $n(\%)$ & $38(42.2)$ \\
\hline Remdesivir, $n(\%)$ & $8(8.9)$ \\
\hline Hydroxychloroquine, $n$ (\%) & $27(30)$ \\
\hline Tocilizumab, $n(\%)$ & $8(8.9)$ \\
\hline Corticosteroids, $n(\%)$ & $48(53.3)$ \\
\hline $\begin{array}{l}\text { Number of different antibiotics utilized } \\
\text { (per patient), median [IQR] }\end{array}$ & $7[4 ; 10]$ \\
\hline Number of bacteremia per patient, mean (SD) & $0.80(3.92)$ \\
\hline Number of VAP per patient, mean (SD) & $0.92(1.05)$ \\
\hline Number of LRTS per patient, median [IQR] & $3[2 ; 4]$ \\
\hline Viral load (log10 copies per mL), median [IQR] & $3.3[1.8 ; 5.2]$ \\
\hline Time to negativity in LRTS, median [IQR] & $29[23 ; 34]$ \\
\hline Mortality 6 weeks, $n(\%)$ & $23(25.6)$ \\
\hline
\end{tabular}

$I Q R$ interquartile range, $B M I$ body mass index, SAPS Simplified Acute Physiology Score, SOFA Sequential Organ Failure Assessment score, ICU intensive care unit, LRTS lower respiratory tract samples, SD standard deviation 

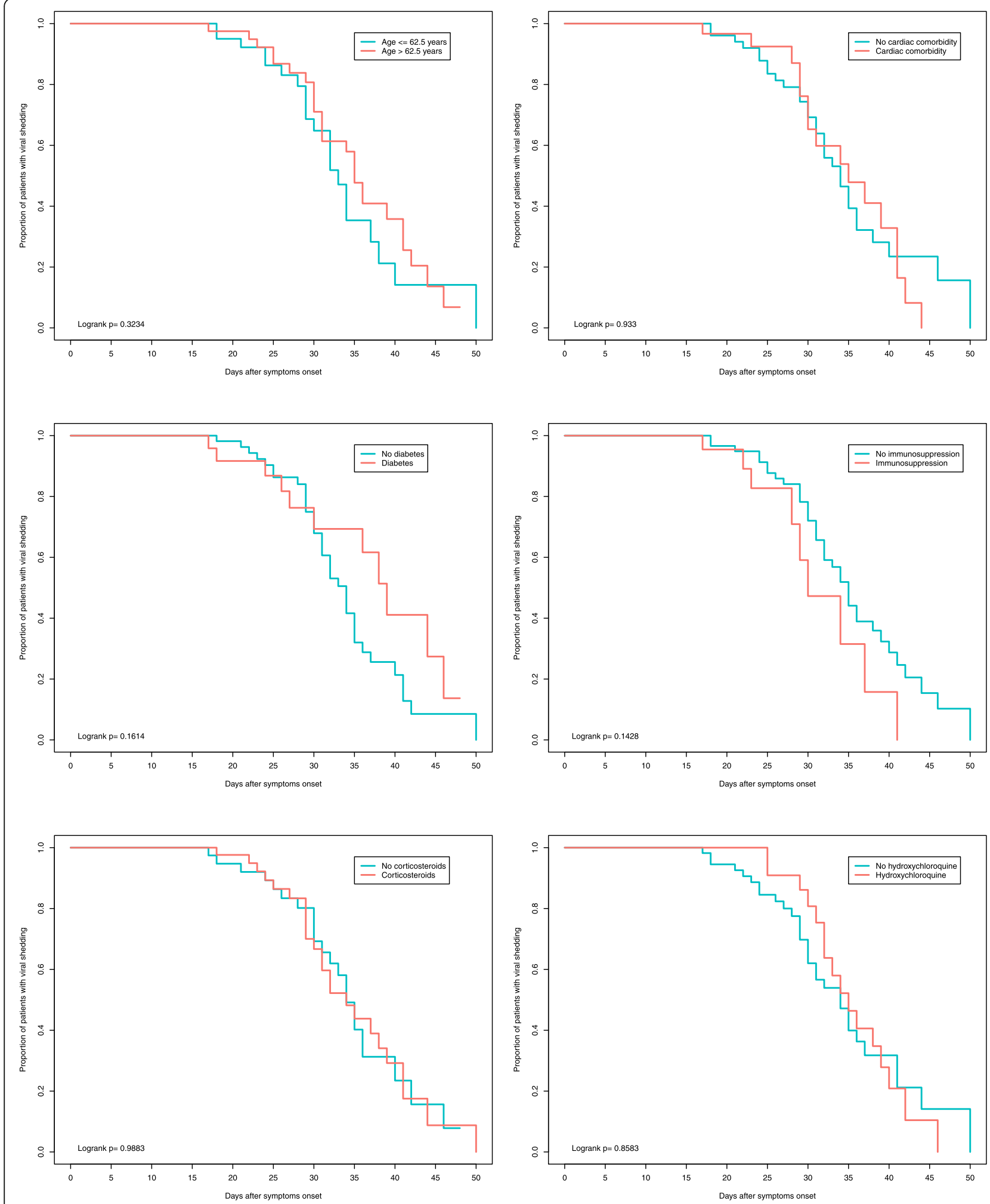

Fig. 1 Viral shedding in lower respiratory tract for the different patient populations, according to patients' characteristics and to treatments received. For this descriptive analysis, we performed a log rank test for the different subgroups 
test was performed; a specific subgroup had prolonged viral shedding if the log rank test between the two groups (e.g., diabetic versus non-diabetic) was statistically significant. Second, we evaluated viral load in LRT during the ICU stay (i.e., quantitative RT-PCT) using graphical and descriptive statistics (i.e., Wilcoxon test) between survivors and non-survivors. Third, we determined the association between viral presence in LRT and mortality using mixed-effect logistic models for clustered data (PROC GLIMMIX of SAS) and adjusting for the time between symptoms' onset and date of sampling. All collected samples were considered for this analysis. These models take into account the clustering effect of multiple sampling per patient and the center effect (i.e., random effect). We performed two sensitivity analyses: the first using only endotracheal aspirates and the second adjusting for sex and age. Tests were twotailed, with $p<0.05$ being considered significant. All analyses were performed using SAS (version 9.4) and R (version 3.5.3). The current analysis complied with the STROBE guidelines for observational studies [16].

\section{Results}

From March to May 2020, 267 LRTS were performed in 90 patients from both centers. A median of 3 (interquartile range [IQR] 2; 4) LRTS was collected per patient. Eighty-three percent $(n=222)$ of LRTS were endotracheal aspirates, whereas a bronchoalveolar lavage was performed in $15 \%(n=41)$ of samples. The median age was 62.5 years (IQR 54; 70), and 71 (79\%) patients were male (Table 1). Thirty-six $(40 \%)$ patients had a chronic heart failure, 27 (30\%) had diabetes mellitus, and 28 (31\%) were immunocompromised. The median SAPS II at ICU admission was 45.5 (IQR 37; 61). Eight (9\%), $38(42 \%), 27(30 \%)$, and $48(53 \%)$ patients received tocilizumab, ritonavir/lopinavir, hydroxychloroquine, and corticosteroids, respectively. Thirty-three patients $(26 \%)$ died within 6 weeks after symptoms' onset. The median time to negativity was 29 (IQR 23; 34) days.

Prolonged viral shedding was not associated with age $(p=0.32)$, cardiac comorbidities $(p=0.93)$, diabetes $(p=0.16)$, immunosuppression $(p=0.14)$, nor corticosteroid use ( $p=0.99$, Fig. 1).

However, using a graphical description, the LRT viral load tended to be higher in non-survivors (Fig. 2).

This difference was statistically significant using mixed-effect models and after adjusting for the time interval between onset of symptoms and date of sampling, patient, and center random effect (OR $3.78,95 \%$ CI $1.13-12.64, p=0.03)$. A sensitivity

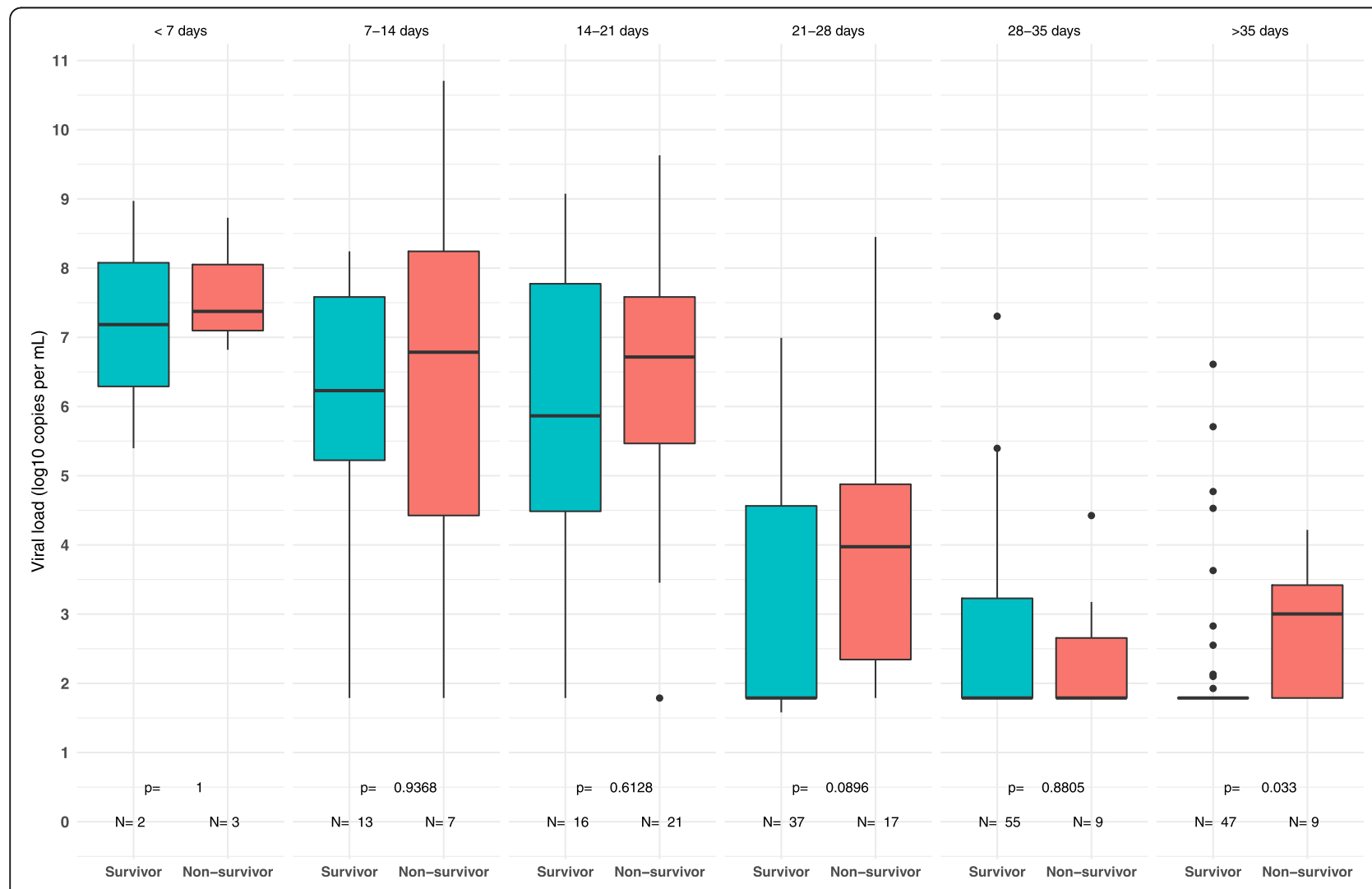

Fig. 2 Viral load among survivors and non-survivors at 6 weeks, stratified by the time between symptoms' onset and date of sampling. For this descriptive analysis, we performed a Wilcoxon test between survivors and non-survivors. N, number of lower respiratory tract samples performed 
analysis using only endotracheal aspirates (i.e., without bronchoalveolar leakage fluid and plugged telescoping catheter) showed similar results (OR 2.96, 95\% CI $0.78-11.25, p=0.10$ ). After adjustment for age and gender, we observed again similar results (OR 3.25, 95\% CI 0.95-11.17, $p=0.06$ ).

\section{Discussion}

Our findings have several clinical, pathophysiological, and infection prevention implications. First, we showed that viral load in the LRT was associated with the 6week mortality. Therefore, positive LRTS may be used as a prognostic marker in COVID-19 patients. Second, COVID-19 is characterized by an initial phase of viral replication in the upper respiratory tract, followed by a second pulmonary phase driven especially by the host inflammatory response [17], and this latter phase probably determines the prognosis of disease. For this reason, some investigators administered immunomodulatory drugs in severe COVID-19 patients [18]. However, our data may suggest a possible direct cytopathic role of virus in the LRT, supported by the significant association between viral load and mortality. Third, we showed that the viral shedding in LRT lasted almost 30 days in median, and we did not identify specific risk factors for prolonged viral shedding in the LRT. Several studies illustrated that viral shedding in the upper respiratory tract in non-critically ill patients varied from 8 to 24 days $[2,5,12-15,19]$. We observed that the viral shedding in critically ill patients may be longer, probably due to a prolonged replication in the LRT. Interestingly, any of the well-known risk factors for upper respiratory tract appeared to be able to influence the viral shedding in LRT. Critically ill patients may, therefore, require prolonged infection prevention measures during their hospitalization.

Our study has several limitations. First, we performed an observational study using surveillance data and we showed only an association between viral presence and mortality. Second, viral cell cultures (i.e., the gold standard) were not routinely performed during the study: the results on viral shedding might have been different if this method would have been used and firm assumptions on infectivity cannot be made. Third, all aspirates (endotracheal samples, BAL, and telescope catheters) were categorized as LRTS and a comparison between them may be debatable. However, a sensitivity analysis using only endotracheal samples showed similar results. Moreover, the LRTS dilution was not standardized between the two participating centers and a dilution marker was not used. Finally, we did not routinely collect nasopharyngeal samples and the true viral excretion (e.g., from the upper respiratory tract) concomitantly with LRT replication remains unknown; therefore, assumptions on infectivity based on LRT analyses should be interpreted with caution.

\section{Conclusions}

The viral shedding in LRT lasted almost 30 days in median in critically ill patients, and the SARS-CoV-2 viral presence in the LRT was associated with the 6week mortality.

\section{Supplementary information}

Supplementary information accompanies this paper at https://doi.org/10. 1186/s13054-020-03323-5.

\section{Additional file 1.}

\section{Abbreviations}

BMI: Body mass index; Ct: Cycle threshold; ICU: Intensive care unit; IQR: Interquartile range; LRT: Lower respiratory tract; LRTS: Lower respiratory tract samples; RT-PCR: Real-time polymerase chain reaction; SAPS: Simplified Acute Physiology Score; SOFA: Sequential Organ Failure Assessment score

\section{Acknowledgements}

The authors thank Céline Féger, M.D. (EMIBiotech), for her editorial support. The authors thank the French COVID-19 study group.

\section{Authors' contributions}

$\mathrm{NB}, \mathrm{PHW}, \mathrm{AL}$, and JFT analyzed and interpreted the data. NB, PHW, JFT, EB, and PPT were responsible for the data collection. NB and PHW were the major contributors in writing the manuscript. All authors read and approved the final manuscript.

\section{Funding}

NB is currently receiving a mobility grant from the Swiss National Science Foundation (Grant Number: P400PM_183865) and a grant from the

Bangerter-Rhyner Foundation. These grants support his fellowship in France. The French center (Bichat University Hospital) was part of the overall French COVID-19 cohort assessing patients with COVID-19 and registered in clinicaltrials.gov (NCT04262921).

Availability of data and materials

The datasets used and/or analyzed during the current study are available from the corresponding author on reasonable request.

Ethics approval and consent to participate

All studies were approved by the national ethics committees.

Consent for publication

Not applicable.

\section{Competing interests}

The authors have disclosed that they do not have conflict of interest. JFT received fees for lectures to $3 \mathrm{M}, \mathrm{MSD}$, Pfizer, and Biomerieux. JFT received research grants from Astellas, 3M, MSD, and Pfizer. JFT participated to advisory boards of 3M, MSD, Bayer Pharma, Nabriva, and Pfizer. BV reports grants, personal fees for lectures, and travel accommodations from Qiagen. $\mathrm{B} V$ received personal fees for lecture and travel accommodation support from BioMérieux. BV received personal fees for lectures from Hologic and Gilead.

\footnotetext{
Author details

${ }^{1}$ University of Paris, INSERM, IAME, F-75006 Paris, France. ${ }^{2}$ Ente Ospedaliero Cantonale, Locarno Community Hospital, Locarno, Switzerland. ${ }^{3}$ Infection Control Program and WHO Collaborating Centre on Patient Safety, University of Geneva Hospitals and Faculty of Medicine, Geneva, Switzerland. ${ }^{4}$ Medical and Infectious Diseases ICU (MI2), Bichat-Claude Bernard Hospital, AP-HP, 75018 Paris, France. ${ }^{5}$ AP-HP, Hôpital Bichat-Claude Bernard, Laboratoire de virologie, F-75018 Paris, France. ${ }^{6}$ Faculty of Biomedical Sciences, Università della Svizzera Italiana (USI), Lugano, Switzerland. ${ }^{7}$ Clinic of Endocrinology and Diabetology, Lugano and Mendrisio Regional Hospital, Ente Ospedaliero Cantonale, Lugano, Switzerland. ${ }^{8}$ Ente Ospedialiero Cantonale, Division of Infectious Diseases, Regional Hospital Lugano, Lugano, Switzerland.
} 
Received: 19 August 2020 Accepted: 4 October 2020

Published online: 16 October 2020

\section{References}

1. Faust JS, Del Rio C. Assessment of deaths from COVID-19 and from seasonal influenza. JAMA Intern Med. 2020;180(8):1045-46. https://doi.org/10.1001/ jamainternmed.2020.2306.

2. Zheng S, Fan J, Yu F, Feng B, Lou B, Zou Q, et al. Viral load dynamics and disease severity in patients infected with SARS-CoV-2 in Zhejiang province, China, January-March 2020: retrospective cohort study. Bmj. 2020;369: m1443.

3. Yu F, Yan L, Wang N, Yang S, Wang L, Tang Y, et al. Quantitative detection and viral load analysis of SARS-CoV-2 in infected patients. Clin Infect Dis. 2020;71(15):793-98. https://doi.org/10.1093/cid/ciaa345.

4. Fang Z, Zhang Y, Hang C, Ai J, Li S, Zhang W. Comparisons of viral shedding time of SARS-CoV-2 of different samples in ICU and non-ICU patients. J Infection. 2020;81(1):147-78.

5. Wolfel R, Corman VM, Guggemos W, Seilmaier M, Zange S, Muller MA, et al. Virological assessment of hospitalized patients with COVID-2019. Nature. 2020;581(7809):465-9.

6. Huang Y, Chen S, Yang Z, Guan W, Liu D, Lin Z, et al. SARS-CoV-2 viral load in clinical samples from critically ill patients. Am J Respir Crit Care Med. 2020;201(11):1435-8.

7. Pujadas E, Chaudhry F, McBride R, Richter F, Zhao S, Wajnberg A, et al. SARS-CoV-2 viral load predicts COVID-19 mortality. Lancet Respir Med. 2020; 8(9):e70. https://doi.org/10.1016/S2213-2600(20)30354-4.

8. ECDC (2020) Guidance for discharge and ending isolation in the context of widespread community transmission of COVID-19. Availbale from: https:// www.ecdc.europa.eu/sites/default/files/documents/covid-19-guidancedischarge-and-ending-isolation-first\%20update.pdf. Last Accessed 15th July 2020. 2020.

9. Lescure FX, Bouadma L, Nguyen D, Parisey M, Wicky PH, Behillil S, et al. Clinical and virological data of the first cases of COVID-19 in Europe: a case series. Lancet Infect Dis. 2020;20(6):697-706.

10. Pan Y, Zhang D, Yang P, Poon LLM, Wang Q. Viral load of SARS-CoV-2 in clinical samples. Lancet Infect Dis. 2020;20(4):411-2.

11. Buetti N, Trimboli PP, Mazzuchelli T, Lo Priore E, Balmelli C, Trkola A, et al. Diabetes mellitus is a risk factor for prolonged SARS-CoV-2 viral shedding in lower respiratory tract samples of critically ill patients. Endocrine. 2020:1-7. https://doi.org/10.1007/s12020-020-02465-4.

12. Fu Y, Han P, Zhu R, Bai T, Yi J, Zhao X, et al. Risk factors for viral RNA shedding in COVID-19 patients. Eur Respir J. 2020.

13. Xu K, Chen Y, Yuan J, Yi P, Ding C, Wu W, et al. Factors associated with prolonged viral RNA shedding in patients with COVID-19. Clin Infect Dis. 2020;71(15):799-806. https://doi.org/10.1093/cid/ciaa351.

14. Xiao AT, Tong YX, Zhang S. Profile of RT-PCR for SARS-CoV-2: a preliminary study from 56 COVID-19 patients. Clin Infectious Diseases. 2020;ciaa460. https://doi.org/10.1093/cid/ciaa460.

15. Qi L, Yang Y, Jiang D, Tu C, Wan L, Chen X, et al. Factors associated with duration of viral shedding in adults with COVID-19 outside of Wuhan, China: a retrospective cohort study. Int J Infect Dis. 2020;96:531-37. https://doi.org/ 10.1016/j.ijid.2020.05.045.

16. von Elm E, Altman DG, Egger M, Pocock SJ, Gotzsche PC, Vandenbroucke $J$, et al. Strengthening the Reporting of Observational Studies in Epidemiology (STROBE) statement: guidelines for reporting observational studies. Bmj. 2007;335(7624):806-8.

17. Siddiqi HK, Mehra MR. COVID-19 illness in native and immunosuppressed states: a clinical-therapeutic staging proposal. J Heart Lung Transplantation. 2020;39(5):405-7.

18. Toniati P, Piva S, Cattalini M, Garrafa E, Regola F, Castelli F, et al. Tocilizumab for the treatment of severe COVID-19 pneumonia with hyperinflammatory syndrome and acute respiratory failure: a single center study of 100 patients in Brescia, Italy. Autoimmunity Reviews. 2020;19(7):102568.

19. Yan D, Liu XY, Zhu YN, Huang L, Dan BT, Zhang GJ, et al. Factors associated with prolonged viral shedding and impact of lopinavir/ritonavir treatment in hospitalised non-critically ill patients with SARS-CoV-2 infection. Eur Respir J. 2020

\section{Publisher's Note}

Springer Nature remains neutral with regard to jurisdictional claims in published maps and institutional affiliations.

Ready to submit your research? Choose BMC and benefit from:

- fast, convenient online submission

- thorough peer review by experienced researchers in your field

- rapid publication on acceptance

- support for research data, including large and complex data types

- gold Open Access which fosters wider collaboration and increased citations

- maximum visibility for your research: over $100 \mathrm{M}$ website views per year

At BMC, research is always in progress.

Learn more biomedcentral.com/submissions 